\title{
Euclides da Cunha: leitor de histórias e romances do século XIX
}

Ricardo Souza de Carvalho

RESUMO: Este ensaio propõe que o romance histórico e a historiografia do século XIX foram decisivos para conformar a singularidade d'Os Sertões de Euclides da Cunha. Ambos os gêneros compartilharam tanto a emoção quanto a veracidade que podem ampliar a discussão sobre a confluência entre "ciência e literatura" presente desde a publicação da obra. Enquanto o romance tornou-se um grande estímulo durante a formação de Euclides como escritor, a concepção de história como ciência e arte proposta por Taine no Essai sur Tite Live (1856) foi um paradigma para Os Sertões.

PALAVRAS-CHAVE: Euclides da Cunha, história, romance, século XIX

ABSTRACT: This essay proposes that the historical novel and historiography of the nineteenth century were decisive in shaping the uniqueness of Os Sertões by Euclides da Cunha. Both genres shared excitement and truthfulness that can broaden the discussion about the confluence between "science and literature", on going since the publication of this work. While the novel has become a major stimulus for Euclides'formation as a writer, the conception of history as a science and as an art form proposed by Taine in Essai sur Tite Live (1856) was a paradigm for Os Sertões. KEYWORDS: Euclides da Cunha, history, novel, 19th century 
Desde a publicação em 1902 e ao longo de uma recepção crítica de mais de um século, tomou-se como ponto de partida para a análise d'Os Sertões de Euclides da Cunha a confluência entre campos do conhecimento ou gêneros diversos. Enquanto as denominações de um dos termos podem variar, em geral o termo vinculado à literatura está garantido. Nossa reflexão, se por um lado prossegue a leitura do caráter compósito da obra euclidiana, por outro pretende recuperar seus paradigmas em dois gêneros que foram decisivos no século xIX e que mantiveram intensas relações entre si, a historiografia e o romance.

Entre os primeiros críticos d'Os Sertões, Araripe Júnior foi o que mais se serviu do romance para tentar compreender a singularidade do livro de estreia de Euclides, por meio dos mais variados exemplos, que vão do romance de aventuras ao romance russo. Logo no início do seu alentado texto dividido em duas partes, Araripe comenta o entusiasmo de que foi tomado - claro que depois de enfrentar as páginas de "A Terra" - apenas comparável às leituras de romances de aventura na infância: "Lembrei-me, então, dos bons tempos em que, ainda menino eu lançava-me perdidamente através dos romances enormes como Monte Cristo, de Dumas, ou os Mistérios do povo, de Eugênio Sue, de respiração opressa, sem tomar fôlego, para só parar na última página, e com a dolorosa saudade de quem abandona uma festa inolvidável". ${ }^{2}$ Quem se manifesta por enquanto é o leitor comum, que remonta ao prazer e ao descompromisso da experiência da leitura na infância, que chegou a supor que não seria possível resgatar o crítico consagrado Araripe Júnior: "A emoção por ele produzida neutralizou a função da crítica". Talvez para Euclides essa tenha sido a melhor crítica recebida por Os Sertões.

Em nenhuma parte de seu artigo Araripe sustenta que Os Sertões seja um romance, mas sim como um romance, ou melhor, como alguns romances. Quando necessita apoiar-se em algum gênero, considera-o história, a qual, a começar pelo seu apelo narrativo, manteve laços estreitos com o mesmo romance durante o século xIx. Além disso, defende que Os Sertões superaria o romance folhetinesco, uma vez que não depende dos surrados recursos para "segurar" o seu leitor: "É raro este sucesso em uma obra de história, ainda mesmo em um romance da extensão daquele livro, quando o autor não se socorre de ficellis e de ocultações propositais, para renovar, de capítulo em capítulo,

1. Juizos críticos: Os sertões e os olhares de sua época. Valentim Facioli e Leonardo do Nascimento, orgs. São Paulo: Nankin Editorial, Editora Unesp, 2003, p. 56.

2. Id.

38 - CARVALHO, Ricardo Souza de. Euclides da Cunha: leitor de Histórias... 
o alento à curiosidade do leitor". ${ }^{3}$ Por isso, uma obra historiográfica que se lê como um romance de Dumas e Sue pode ser o antecessor mais apropriado para Os Sertões, como os dez volumes da História da Revolução francesa (1847-1853), de Jules Michelet, a partir da qual Araripe traça mais de um paralelo:

Ali como aqui o escritor, descrevendo a vida de uma colmeia humana, dedilha toda a gama da perversidade existente em seres pensantes. Ali como aqui a tragédia da insânia coletiva multiplica-se em quantidade e qualidade. Desta sorte, diante da variedade de espetáculos, em que fazem ato de presença todos os secretos instintos, todas as bestialidades, todas as violências do homem, não se respira enquanto se tem o livro diante dos olhos. Devoram-se os acontecimentos descritos, perdidas as noções do tempo e da resistência ao trabalho. Com a avidez do náufrago, soçobrado, entre os marulhos das tempestades psíquicas, não se reflete sobre o que se vê, vive-se a miséria dos desgraçados que tripudiam sob a vara mágica do escritor; e no fim sucumbe-se. ${ }^{4}$

Araripe não desenvolve esse parentesco entre as obras de Euclides e Michelet, porém muito mais adiante retoma a referência ao romance, dessa vez com a modalidade que explicitamente se envolveu com a história no século xIX. Ao comentar o primeiro enfrentamento entre o exército e os canudenses, apoia-se no mestre do romance histórico:

Estamos em pleno romance de Walter Scott; e só então compreende-se como o escritor escocês pôde recolher, sem grande trabalho, fatos verdadeiros das lutas dos highlanders para orná-las com as suas ficções poéticas.

A realidade dessas grandes guerras é talvez superior em efeitos ao que possa criar a inventiva humana. ${ }^{5}$

Nesse ponto, o crítico alude à sinuosa parceria entre realidade e ficção que perpassa o romance histórico e também obras de história como Os Sertões, mas sem enfrentá-la. A dupla perspectiva da história e do romance n'Os Sertões é ratificada ao unir, em uma mesma frase, um historiador militar da Antiguidade e um dos maiores romancistas do século

3. Id., p. 57 .

4. Id.

5. Id., p. 70 . 
XIx: "Lembra ao mesmo tempo Xenofonte e Flaubert". ${ }^{6}$ Araripe talvez pensasse tanto no romancista de Madame Bovary, que retrata a sociedade de seu tempo como um historiador anseia pela veracidade, quanto no romancista de Salambô, que recria um passado remoto.

Como se ainda todas essas referências não fossem suficientes para dar conta das nuances d'Os Sertões, Araripe, motivado pelo drama dos soldados obcecados por Canudos, traça uma ousada comparação com Dostoievski: "Esta situação terrível o sr. Euclides da Cunha descreve nos detalhes militares com intensidade quase igual à dos romances de Dostoievski, que foi um dos maiores, senão o maior dos psicólogos das multidões, produzido pelo século Xıx"? O "quase igual”, além de não equiparar Euclides a Dostoievski, sinalizaria que Os Sertões, por mais que se pareça, não é um romance, assim como outras obras de história do século XIX.

Tal fixação pelo romance pode ser explicada pelas realizações de Araripe no gênero, sob a inspiração de José de Alencar, antes de se dedicar à crítica. Entre eles, O Reino Encantado: crônica sebastianista (1878) mereceu uma nota de rodapé na segunda edição d'Os Sertões, no final do célebre capítulo III de "O Homem": "Sobre a Pedra Bonita, leia-se o livro de Araripe Júnior, O Reino Encantado, onde o acontecimento, brilhantemente romanceado, se desdobra em todos os aspectos emocionantes". $\mathrm{O}$ elogio de Euclides, significativamente calcado no critério da emoção, repete-se em carta endereçada ao crítico de 30 de março de 1903, aproveitando a ocasião para expressar seu apreço pelo romance histórico e sua escassez no Brasil:

[...] Penso que o senhor é injusto no aniquilar aquele seu trabalho, talvez porque o tenha escrito dia a dia para rodapé de um jornal. Sem lisonja, considero-o. Pena é que tivesse abandonado aquela trilha. Não temos romances históricos, sendo a nossa vida nacional tão farta de episódios interessantíssimos e originais. A este propósito, estou quase a lhe dar o mesmo conselho que me deu há poucos dias, em carta, o dr. Lúcio de Mendonça: aviventar com a fantasia criadora um dos mil incidentes da nossa história. Temos quadros e sucessos que fariam o delírio de Dumas e Walter Scott. ${ }^{9}$

6. Juizos críticos, p. 79.

7. Id., p. 80.

8. Os Sertões: (campanha de Canudos). Ed. Leopodo Bernucci. São Paulo: Ateliê Editorial, Imprensa Oficial do Estado, Arquivo do Estado, 2001, p. 249.

9. Correspondência de Euclides da Cunha. Walnice Nogueira Galvão e Oswaldo Galotti, orgs. São Paulo: Edusp, 1997, p. 160.

40 - CARVALHO, Ricardo Souza de. Euclides da Cunha: leitor de Histórias... 
Embora Euclides não tenha cumprido o conselho de Lúcio de Mendonça, o romance histórico e a historiografia marcados por ele tiveram um papel fundamental em sua formação como escritor. Já em 1887, quando cursava o segundo ano da Escola Militar da Praia Vermelha, escreveu em seu caderno de cálculo infinitesimal o manuscrito em prosa "93", recentemente divulgado por Leopoldo Bernucci e Francisco Foot Hardman na edição da Poesia reunida. Motivado pelo romance histórico em torno da Revolução Francesa, o Quatrevingt-treize (1874), de Victor Hugo, o jovem Euclides deixa-se envolver por uma História revivida com toda a comoção possível:

Tenho diante de mim uma página de V. Hugo; é através dessa lente extraordinária que vejo esse amálgama formidável de luzes e trevas - de lágrimas e sangue -; essa loucura pavorosa de um povo sobre a qual, antítese extraordinária - rebrilha a consciência eterna da História...

$[\ldots]$

Foi, por certo, terrível aquela época; foi de certo fatal aquela explosão formidável de cóleras acumuladas em dezesseis séculos; a sombra pavorosa da populaça - essa hidra de milhares de corpos e uma só cabeça - Marat; [...] em toda aquela sublimidade houve muito crime horroroso e cruel; muitos heróis, na ebriez da luta, empunhavam o ferro de Caco; muitos miseráveis empunharam o punhal de Bruto; vibravam, palpitaram naquela convulsão enorme todas as cambiantes do sentimento humano; há ali o sublime - a tomada da Bastilha; o horrível, a morte de Antonieta, [...].10

Alguns anos depois, Euclides continuava fiel ao romance histórico com o Ivanhoe (1820), de Scott - "obra-prima velhíssima" nas suas próprias palavras ${ }^{11}$ - e com $L a$ Débâcle (1892), o 19º volume da série Rougon-Macquart, de Émile Zola. A reconstituição da guerra franco-prussiana em 1870 despertou a admiração de Euclides, para quem esse era o melhor livro do romancista francês: "[...] Com certeza notaste o extraordinário contraste entre o trabalho calmo e indiferente do velho Camponês ao lado do espantoso fragor de uma batalha -; poucas páginas tenho lido tão comovedoras como essa em que Zola fecha um capítulo estrugidor e fulgurante, cheio de metralhadoras e mortes

10. Poesia reunida. Leopoldo M. Bernucci e Francisco Foot Hardman, orgs. São Paulo: Editora da UNESP, 2009, pp. 295-6.

11. Carta de 25 de novembro de 1893 a Porchat. Correspondência de Euclides da Cunha, op. cit., p. 53. 
e extraordinários heroísmos, com aquela nota profundamente humana e tranquila". ${ }^{12}$ Os elogios para o romancista que se baseia na história - "comovedoras", "estrugidor", "fulgurante", "humana" - logo se transformariam em metas para o historiador que se baseia no gênero romance.

Em 1897, a caminho de Canudos, os romances acompanhavam Euclides. Em sua caderneta de campo, em meio a anotações várias sobre a terra, a população e a guerra, que seriam aproveitadas n'Os Sertões, registrou frases de Os fidalgos da Casa Mourisca (1871), de Júlio Dinis, e de As minas de prata (1865-1866), de Alencar. Do capítulo xxII do romance português, transcreveu um fragmento da descrição de um amanhecer: "[...] Ao nascente, no seio de um denso cúmulo de vapores amarelados, desenhava-se vagamente o majestoso íris. $\mathrm{O}$ verde das árvores e dos prados recebia desta luz uma cambiante mais viva". Do extenso romance histórico do brasileiro, alguns trechos e significados de palavras dos capítulos III e vi da primeira parte, como "revestido de guisamentos sacerdotais" e "Achou-se em uma longa crasta subterrânea". Na página seguinte da caderneta, depois da indicação da data, " 28 de Setembro", e da anotação "Bombardeio", seguem-se apontamentos soltos; entre eles, a indicação "Fronte senhoril/ a lordly fore-head de Walter Scott". Tais apontamentos romanescos em pleno cenário de guerra, seja ligados a outras intenções, seja requeridos pela obra em gestação, ratificam o vivo interesse de Euclides pelo gênero. ${ }^{13}$

Euclides apresentou Os Sertões, antes de tudo, como História, desde o projeto inicial de fazer a "história da Campanha de Canudos" até a feição última de denunciar um crime, esperando fazer "jus ao admirável conceito de Taine sobre o narrador sincero que encara a história como ela merece". Estamos no final da "Nota preliminar", em que Euclides cita passagem do ensaio do francês sobre o historiador Tito Lívio: “... ele se irrita contra as meias-verdades que são meias-falsidades, contra os autores que não alteram nem uma data, nem uma genealogia, mas deformam os sentimentos e os costumes, que conservam o desenho dos acontecimentos e mudam a cor, que copiam

\footnotetext{
12. Carta de 20 de agosto de 1892 a Porchat. Id., p. 36.

13. Em sua edição da Caderneta de campo, Olímpio de Souza Andrade não identificou a fonte das citações, além de explicá-las como "palavras, expressões, frases soltas, aparentemente sem ligação com algo mais longo e inteiriço e sem razão aparente de existir"; "[...] anotações relativas a lembranças de coisas ouvidas no sertão, anotadas mais tarde junto a outras ocorridas ao próprio anotador, ou provenientes de leituras que fazia ou fizera há pouco tempo". (São Paulo: Cultrix; INL/MEC, 1975, pp. 182-3).
}

42 • CARVALHO, Ricardo Souza de. Euclides da Cunha: leitor de Histórias... 
os fatos e desfiguram a alma: ele quer sentir em bárbaro, entre os bárbaros, e, entre os antigos, em antigo". ${ }^{14}$

O Essai sur Tite Live (1856), republicado várias vezes no século XIX - em 1896 alcançava a sexta edição, o que dá uma medida do reconhecimento do autor -, com certeza não teria sido o único livro de Taine consultado por Euclides. Já se afirmou mais de uma vez que a divisão d'Os Sertões em "A Terra", "O Homem" e "A Luta" deve à fórmula raça - meio - momento, proposta na Introdução à História da Literatura Inglesa (1863). Além disso, Euclides encarava Taine, ao lado do português Camilo Castelo Branco, como "velhos amigos", ${ }^{15}$ revelando o constante entrecruzamento entre história e romance em seus interesses literários.

Não apenas o trecho transcrito quase como epígrafe a Os Sertões, mas o livro inteiro de Taine pode ser considerado como meio privilegiado para se entender a concepção de história de Euclides. As perguntas que Taine se fazia no "Prefácio" foram repassadas para mais de uma geração:

[...] Pode-se empregar na crítica os métodos exatos? Um talento pode ser expresso por uma fórmula? As faculdades de um homem, como os órgãos de uma planta, dependem uns dos outros? Eles são medidos e produzidos por uma lei única? Dada esta lei, pode-se prever sua energia e calcular do seu avanço seus bons e seus maus efeitos? Pode-se reconstruí-los, como os naturalistas reconstroem um animal fóssil? E existe em nós uma faculdade mestra, na qual a ação uniforme se comunica diferentemente a nossas engrenagens, e imprime a nossa máquina um sistema necessário de movimentos previstos. ${ }^{16}$

As respostas nessa e nas obras seguintes configuraram uma crítica científica aplicada ao estudo do homem e de suas criações que esteve na base da obra euclidiana. Por outro lado, a busca de Taine por "métodos exatos" e uma "lei única" não o impediram de reconhecer outras vertentes menos determináveis. Sintomaticamente, o Essai sur Tite Live divide-se em duas partes, que, em lugar de serem antagônicas, podem

\footnotetext{
14. Tradução nossa. Os Sertões, op. cit., p. 67.

15. Ver cartas de 19 de janeiro de 1902 e 17 de setembro de 1902. Correspondência de Euclides da Cunha, op. cit., pp. 130; 138.

16. TAIne, Hippolyte. Essai sur Tite Live. 6. ed. Paris: Librairie, 1896, pp. viI e viII.
} 
conciliar-se: "A História considerada como uma ciência" e "A História considerada como uma arte".

O trecho escolhido por Euclides encontra-se no primeiro capítulo da parte I, intitulado simplesmente "A crítica". O brasileiro dispensou o esclarecimento de Taine de que a história merece ser tratada como "ciência", preferindo a subjetividade contida na expressão "narrador sincero". Acompanhemos a passagem que antecede a transcrita para recuperar o "modelo ideal" de historiador sugerido por Taine: "[...] ele tem apenas por dever e por desejo suprimir a distância dos tempos, de colocar o leitor face a face com os objetos, de torná-lo concidadão dos personagens que ele descreve e contemporâneo dos acontecimentos que ele conta. Agora, que venham os moralistas e dissertem sobre o quadro exposto; sua tarefa acabou; ele deixa-lhes o lugar e vai embora. Pois ele ama apenas a verdade absoluta [...]". Percebemos, então, que tal "verdade absoluta" não estaria nem na lição transmitida, nem na fidelidade a informações pontuais, mas sim uma verdade mais íntima que recupere a "vida" da história. $\mathrm{O}$ trecho que vem a seguir ao citado confirma que Taine ainda navega nas águas da tradição romântica da história: "[...] Eis que sai do seu século para ressuscitar em si mesmo as paixões originais, as crenças estrangeiras, o caráter esquecido de outros povos e de outras épocas. Sobre toda a rota do tempo, ele segue as mudanças insensíveis, e ele acha que ao fim uniu e desenvolveu, no recinto estreito do seu espírito, o sentimento e toda a vida de uma nação". Além disso, eles devem ser animados pelo "amor da prova" e o espírito crítico.

Mais adiante, no capítulo Iv, "A filosofia na História”, Taine faz uma ressalva para o modo de se expressar a lei universal que determinaria os acontecimentos históricos: "É necessário por isso abandonar a narração e compor catálogos de fatos determinados por fórmulas geométricas? Um escrito pode ser filosófico e continuar vivo. Para explicar os acontecimentos, basta dispô-los na ordem conveniente; ou seja, sua causa é que dará seu lugar; e a arte de filosofar não é mais do que a arte de compor. Coloquemos juntos aqueles que são os efeitos de uma mesma causa, ou que vão em direção a um mesmo fim. Conservemos na ciência as semelhanças que eles têm na natureza; [...]". Antecipando o tema da segunda parte do seu estudo, Taine considera a História como "narração" cuja "arte de compor" estaria a serviço dos princípios científicos. Ao lado da ordenação em função das relações de causa, efeito ou finalidade, em lugar da dissertação que interrompe a condução "natural" da história, defende uma escolha entre os fatos, em lugar da lentidão da história que pretende contar todos os fatos. E nesse ponto Euclides desviou-se parcialmente da lição de seu mestre: “[...] Acredita-se enfim que é necessário tantas palavras para exprimir uma lei ou indicar uma causa? As principais 
são os caracteres dos climas e dos povos. Em um retrato de seis linhas, se for vivo e verdadeiro, aprende-se mais do que em um volume de dissertação. A imaginação tem isso de admirável, que um adjetivo bem colocado representa-lhe toda uma região ou toda uma nação". Sabemos que Euclides precisou bem mais de seis linhas para explicar o "clima" e o "povo" de sua história, incluindo duas monografias intituladas "A Terra" e o "O Homem", mesmo sob o risco de comprometer o interesse pela sua história. Por mais que se tenha valido da "imaginação", dos adjetivos "bem colocados", a explicitação da ciência n’Os Sertões antes da história propriamente dita pareceu-lhe necessária seja para cobrir lacunas nos estudos brasileiros, seja para não ser tido apenas como um historiador que faz literatura.

Foi efetivamente em "A Luta" que Euclides colocou em execução a proposta da segunda parte do livro de Taine, "A História considerada como uma arte". Tudo indica que as formulações do francês devem ter lhe servido como parâmetro. A ciência se tornaria arte a partir da confluência entre os ofícios: “[...] O artista no historiador não é separado do sábio. Os dois gênios se ajudam, ou até mesmo há apenas um, que ora prepara e raciocina, ora dá acabamento e conta, e, aplicado duas vezes ao mesmo objeto, descobre, pela mesma clarividência, antes a verdade, depois a vida". ${ }^{17}$ Dessa maneira, as partes da arte - retrato, narração, estilo e expressão - seriam produtos da ciência.

Na conclusão, Taine busca demonstrar que o exemplo de Tito Lívio ainda poderia ser válido para os historiadores modernos, muitas vezes entregues à erudição ou à ciência:

[...] Enfim aprende-se dele que é necessário fundir a filosofia no relato; ela não pode estar separada, porque é a sua alma; e deve-se percebê-la apenas pela ordem em que está colocada; aquele que a cada instante interrompe para pensar sobre os efeitos e as causas não é mais um artista, mas um erudito. Não nos esqueçamos que a história é sobretudo uma narração, que Tito Lívio indicou melhor a corrupção insensível de Roma enumerando a cada ano os crimes dos generais, do que dando à parte uma fórmula árida, e que trocando as teorias em discurso, ele as trocou por fatos. Na história, há o crítico que verifica os fatos, o erudito que os recolhe, o filósofo que os explica; mas todos os personagens ficam ocultos atrás do poeta que conta. Eles lhe sopram as palavras e não falam. [...]. ${ }^{18}$

17. Id., p. 190.

18. Id., pp. 356-7. 
Segundo Taine, enquanto os modernos se voltavam demasiado à ciência e aos detalhes particulares, Tito Lívio, por sua vez, voltou-se demasiado à arte e aos traços gerais. Contudo, ao se avaliarem as contribuições de ambos à história, caberia ao historiador romano o primeiro lugar por meio de sua eloquência, uma vez que ela é capaz de reproduzir as paixões humanas em um estilo perfeito. Talvez Euclides tenha feito seu tributo aos modernos em "A Terra" e "O Homem", e aos antigos Heródoto, Xenofonte e Tito Lívio em "A Luta". Os Sertões materializam a divisão da "história como uma ciência" e da "história como uma arte" que Taine queria ver fundidas, mas que ainda no século XIX seriam fortemente separadas. A história afirmava-se como disciplina à medida que se distanciava da "eloquência" e das "paixões" da literatura. Fustel de Coulanges, do alto da cátedra de História Antiga da Escola de Roma, em 1875, defende que a história não é uma "arte que vise narrar com encanto" e que "não se assemelha nem à eloquência nem à poesia", mas sim uma "ciência pura, uma ciência como a física ou como a geologia" que "visa apenas encontrar fatos, descobrir verdades". ${ }^{19}$

Até o próprio Taine sofreu os reveses da institucionalização da história. Sua monumental obra como historiador, Les Origines de la France contemporaine seis volumes publicados entre 1875 e 1893, dos quais três são dedicados à Revolução Francesa -, recebeu uma condenação de Alphonse Aulard, primeiro titular em 1885 da cadeira de história da Revolução Francesa na Sorbonne. Seu livro Taine historien de la Revolution française (1907) ganhou uma resenha de José Veríssimo, um dos responsáveis anos antes pela consagração d'Os Sertões como obra de "ciência e literatura", embora alertasse o abuso dos termos científicos no estilo de Euclides.

Veríssimo aproveita o começo de seu artigo para lembrar a poderosa ascendência de Taine no Brasil, que juntamente com "Spencer, Comte e Renan" fora "um dos grandes escritores europeus que mais influenciaram o nosso espírito, ou, pelo menos, mais o abalaram, pois não sei até onde podemos aqui verificar influências profundas e sérias". ${ }^{20}$ Após apontar as deficiências que a obra historiográfica de Taine já recebera, $\mathrm{o}$ crítico passa ao trabalho de Aulard, considerado o "tiro de misericórdia". Apresenta-o com a credencial de "maior autoridade em história da Revolução francesa" e, portanto,

19. Apud hartog, François. O século Xix e a história: o caso Fustel de Coulanges. Trad. Roberto Cortes Lacerda. Rio de Janeiro: Editora UFRJ, 2003, p. 305.

20. Veríssimo, José. Homens e couzas estrangeiras. $3^{\mathrm{a}}$ série (1905-1908). Rio de Janeiro: H. Garnier, Livreiro-Editor, 1910, p. 381.

46 • CARVALHO, Ricardo Souza de. Euclides da Cunha: leitor de Histórias... 
a partir de suas qualificações como especialista na universidade, contrasta-o em relação às pretensões literárias de Taine:

[...] Estudando-a há trinta anos, com afinco e capacidade, e a instrução especial que tal estudo exigia, recomendados e melhormente prezados processos e métodos de investigação e crítica histórica, baseando-os numa erudição solidíssima e, senão alumiada por um grande talento como o de Taine, servida por uma inteligência de primeira ordem e uma rara probidade científica. E como se não presume de artista e não sacrifique como tanto, e quiçá com tão grande prejuízo seu fez Taine, à glória literária, não disputa posições nem proeminências, nem fama mundana, encerrou-se nos seus estudos com a abnegação e o trabalho de um beneditino. ${ }^{21}$

O resultado desse trabalho em um novo monastério que se chama a cátedra universitária são edições críticas de documentos e uma Histoire politique de la Revolution Française (1901) de mais de oitocentas páginas, a qual, apesar de não ter "o brilho, a arte literária e as fosforescências de pensamento e de estilo de Taine, é, no seu gênero, talvez a obra mais perfeita e sólida hoje existente sobre a Revolução". ${ }^{22}$ Aquilo que parecia "moderno", quando da supremacia de Taine no século xIX, revela-se como "falta" diante da ciência e da erudição de Aulard. Portanto, ele está apto para acionar uma "inquisição minuciosa" - mais uma imagem tomada por Veríssimo para qualificar esse novo fenômeno da especialização - contra a obra de Taine, acompanhando-a "quase pari passu verificando-lhe as fontes, as citações, as referências, as informações, achando-o quase sempre em faltas de exação, de fidelidade nas citações e transcrições, inexato no contar e descuidado, apressado e leviano na consulta e estudo das fontes". ${ }^{23}$

Veríssimo, por mais que em seu trabalho como crítico literário tenha se esforçado em privilegiar a dimensão estética da literatura, endossa o severo julgamento de Aulard por meio de um tratamento específico da história:

[...] Se ela não atinge as qualidades propriamente literárias de Taine, porventura o fundamento mais sólido do seu renome, para os que preferem a verdade a Platão, o historiador,
21. Id., p. 394 .
22. Id., p. 394.
23. Id., pp. 394-5. 
especialmente o historiador da Revolução, sai deste processo desautorizado. Em obras como aquela que escreveu Taine, quiçá em qualquer outra, há alguma cousa que vale mais que o talento, o estilo, as galas e louçanias da forma e ainda do fundo literário, é a probidade intelectual. ${ }^{24}$

Se diferentes critérios de avaliação para a literatura e para a história já valiam na Europa, no caso brasileiro, sem cátedras de história e especialistas em cursos superiores, o critério literário predomina sobre os demais. Tal situação permite que Os Sertões sejam o cartão de visitas para o ingresso de Euclides na Academia Brasileira de Letras, e que em seu discurso de posse de 18 de dezembro de 1906 recorra ao historiador inglês do século XIX, Thomas B. Macaulay, "no demarcar nesta esfera literária um domínio comum da fantasia e da razão, destinado aos eleitos que sejam ao mesmo passo filósofos e poetas". ${ }^{25}$ Foi a melhor opção para um apaixonado pelo romance histórico que desejava parecer cientista.

Ricardo Souza de Carvalho é professor de Literatura Brasileira na Universidade de São Paulo e autor do livro A Espanha de João Cabral e Murilo Mendes (Editora 34, 2011), $1^{\circ}$ lugar na categoria Teoria/crítica literária do 54 Prêmio Jabuti (2012).

24. Id. pp. 396-7.

25. Obra completa. v. 2. Afrânio Coutinho, org. 2. ed. Rio de Janeiro: Nova Aguilar, 1995, pp. 233-4. 